\title{
MERCOSUR COMO POLÍTICA EXTERIOR ARGENTINA Y SUS DESAFÍOS ACTUALES
}

\author{
Alejandro Simonoff \\ Profesor Titular Ordinario de Historia General VI de la Facultad de Humanidades y \\ Ciencias de la Educación, Universidad Nacional de La Plata, Argentina
}

E-mail: asimonoff2010@gmail.com

Orcid: 0000-0003-4125-0535

http://dx.doi.org/10.1590/0102-123146/112

Si bien el Mercosur fue creado al calor de la oleada neoliberal del fin de la Guerra Fría como forma de acceder a la globalización mediante un bloque comercial y que tuvo como filosofía al regionalismo abierto, ello no significó que no fuera un instrumento eficaz para garantizar una inserción equilibrada para Buenos Aires con el mundo a partir de una estructura triangular (Argentina, Brasil y Estados Unidos).

Este impulso tuvo un quiebre entre el fin del anterior milenio y los comienzos del nuevo, en que las crisis brasileña y argentina, entre otras, pusieron en cuestionamiento el funcionamiento del bloque bajo los influjos del Consenso de Washington y permitieron una integración más política.

Sin embargo, la pretensión de la tríada (Estados Unidos, Europa y Japón) de profundizar su proyecto global y el ascenso chino se presentan como desafío para nuestro instrumento de integración regional. Estas son las cuestiones que desarrollaremos en el presente texto. 


\section{La hiperglobalización occidental}

El impulso de la hiperglobalización por parte de la tríada desde los años 1970 consistió en "la integración internacional de los mercados de bienes de capital (pero no de mano de obra) se convirtió en un fin en sí mismo, eclipsando a las políticas nacionales" (Rodrik, 2011, p. 96). Como ha apuntado John Mearsheimer (2019), este fenómeno "ha causado una serie de problemas económicos importantes que han socavado la legitimidad del orden mundial liberal en los estados que forman el núcleo de ese sistema" (p. 39).

En este marco, el fracaso de la Cumbre de la Organización Mundial de Comercio (OMC) de 2003 resultó un punto de quiebre en el programa hiperglobalista llevado adelante por la elite neoliberal. Allí, se rechazó la profundización de la agenda económica internacional impulsada por los países del G8 ${ }^{1}$ y por miembros de la tríada, que consistía en la ampliación de la comercialización e incorpora-

124 ción de normas referidas a la competencia, a movimientos de capitales, propiedad intelectual, desregulación laboral, inversiones y cooperación en rubros como energía, medio ambiente, etcétera. ${ }^{2}$

Claramente, esa reunión marcó el cenit de la oleada neoliberal de fines de la Guerra Fría, en que hubo claramente un avance del poder trasnacional sobre el estatal. Esa profundización del modelo neoliberal tuvo un freno por parte del G22+ que trabó aquellas intenciones. ${ }^{3}$

En este contexto, el Mercosur resultó central para la coordinación política que lo consolidó como instrumento para la inserción internacional argentina cuando con

\footnotetext{
1 Es el acrónimo del grupo de países formados por Canadá, Estados Unidos, Francia, Italia, Alemania, Reino Unido, Japón y Rusia (excluido en 2014).

2 Conocida como propuesta OMC-plus.

3 El G22 está integrado por los principales exportadores de materias primas que pudo frenar el acuerdo cerrado sobre los subsidios que tenían Estados Unidos y la Unión Europea para la reunión de Cancún.
} 
posterioridad a la crisis de 2001 se viró hacia una estrategia más defensiva frente a la hiperglobalización.

Toda esta situación mostró el aumento del peso de los países emergentes en el sistema internacional. Por ello, desde la tríada se impulsó la ampliación del consorcio internacional global, el G8, con la revitalización a fines del mandato de George W. Bush del G20 financiero en un intento de sumarlos al nuevo concierto global. ${ }^{4}$

Sin embargo, y a diferencia de lo ocurrido en el G8, el G20 no contó con la misma homogeneidad, cuestión que afectó la posibilidad de establecer políticas comunes. Por ello, la administración de Barack Obama complementó esta estrategia con otra más: la reconstrucción de la agenda OMC-plus a partir de la promoción de los llamados Acuerdos Transpacífico (TTP por sus siglas en inglés) y Transatlántico (TTIP por sus siglas en inglés), que buscaban imponer los temas bloqueados en Cancún. Los "nuevos" principios fueron promovidos por parte del demócrata mediante la estrategia de "pinzas de cangrejo" sobre Beijing, como la denominó el economista Matthew Cooper, con el objetivo de controlar y fijar las reglas del comercio y de las inversiones (Cooper en Montesa y Azcárate, 2015).

Ante esta situación, las elites sudamericanas tuvieron un cambio de posición en torno al año 2010, y en ello fue importante el rol de algunas organizaciones empresariales, como la Federación de Industrias del Estado de San Pablo (FIESP). La amenaza que aquellos acuerdos cerrasen el acceso a fuentes occidentales de inversiones si no se aceptaban los criterios OMC-plus los llevó a apoyar esas políticas.

Ello explica el retorno a las negociaciones con la Unión Europea (UE), cuyo origen se encontraba en la firma del

\footnotetext{
4 Originalmente el G20 financiero tuvo su primera reunión en diciembre de 1999 en Berlín como un foro que reconociera a los principales países emergentes, subrepresentados en los organismos multilaterales tradicionales, y se lo revitalizó cuando se le otorgó nivel presidencial en 2008.
} 
Acuerdo Marco con la Comunidad Económica Europea en 1995, que estableció los marcos para las negociaciones entre ambos bloques comerciales, y en la Primera Cumbre Unión Europea-América Latina y Caribe de junio de 1999, cuando se afirmó la voluntad de ambos mercados de crear una asociación interregional, aunque estas negociaciones -a cargo de Carlos Menem- como en las sucesivas reuniones ya durante la gestión de Fernando De la Rúa- estuvieron obstaculizadas por las discusiones por subsidios a las exportaciones, ayudas a los campesinos, los precios de entrada de referencia, los picos arancelarios y otras restricciones paraarancelarias por las normas sanitarias y fitosanitarias europeas. Por ello, el gobierno argentino, conjuntamente con los demás miembros del Mercosur, pidieron la eliminación previa de estas distorsiones y trabas al comercio recíproco para avanzar en las discusiones.

A comienzos de la segunda década del nuevo milenio, 126 el proceso negociador tomó nuevos bríos, pero fue limitado por las políticas más proteccionistas de Argentina, así como por la desconfianza del mundo agrícola europeo. En 2013, esta desconfianza se aceleró por la decisión de Brasil de impulsar el acuerdo sumando a Paraguay y a Uruguay, pero la Argentina apareció poco dispuesta, lo que generó un sinnúmero de tensiones y presiones entre Brasil y Argentina, aportando un elemento más en el complejo escenario bilateral (Simonoff, 2014).

La llegada de Mauricio Macri al gobierno argentino y el proceso de destitución de Dilma Rousseff permitieron abrir una nueva instancia de negociaciones con el Viejo Mundo. El primer encuentro se realizó entre el 20 y 24 de marzo de 2017, luego de un impasse de casi cinco años, con un gran entusiasmo por parte de los países del Sur, pero se encontró con otras prioridades por parte del Viejo Continente, como la reconstrucción de la tríada ante la defección norteamericana por la llegada de Donald Trump por medio 
de la firma de acuerdos económicos con Japón, México, Chile, y Canadá, todos miembros del Tratado Integral y Progresista de Asociación Transpacífico (Comprehensive and Progressive Agreement for Trans-Pacific Partnership, CPTPP, o TPP-11) (Simonoff, 2017). ${ }^{5}$

En las negociaciones existieron resistencias europeas a la ampliación de los cupos de exportaciones de carne y etanol, y los sudamericanos sostuvieron que el proceso de desgravación de los bienes industriales debe ser de unos 10 o 15 años, y que debería encararse de forma "gradual y responsable" (Simonoff, 2018).

Luego de dos intentos de anuncios frustrados en las cumbres de Buenos Aires de la OMC (2017) y del G20 (2018), finalmente se realizó una reunión de este último grupo en Osaka (2019) bajo el título "Acuerdo de Asociación Estratégica entre Mercosur y la Unión Europea”. Fue presentado como algo más que un acuerdo en materia comercial; en ese sentido el gobierno argentino señaló que buscó "un vínculo político, cultural y económico estratégico y permanente con la Unión Europea” (Mercosur, 2019).

La decisión del bloque conosureño se vio reforzada por la necesidad de anunciarlo antes de la campaña electoral argentina (Niebieskikwiat, 2019a), y desde el lado europeo, la decisión del presidente del gobierno español, el socialdemócrata Pedro Sánchez, junto a otros seis jefes de Estado (Merkel de Alemania; Costa de Portugal; Rutte de los Países Bajos; Babis de República Checa; Karins de Letonia; y Lofven de Suecia), quienes elevaron una nota al presidente de la Comisión Europea, Jean-Claude Juncker, en que señalaron que se "haga lo posible para culminar ya las negociaciones con el Mercosur" (Idafe, 2019).

$5 \quad$ Es un tratado de libre comercio suscripto por varios países de la Cuenca del Pacífico, Australia, Brunéi, Canadá, Chile, Japón, Malasia, México, Nueva Zelanda, Perú, Singapur y Vietnam, y firmado el 4 de febrero de 2016 en Nueva Zelanda. 
Los resultados concretos de la negociación han sido por lo menos desparejos; más allá de la proclamada adhesión a los principios del libre cambio, nos encontramos con que todos los puntos que los europeos buscaron en el acuerdo fueron logrados, ${ }^{6}$ mientras que las cuotas reclamadas desde la Argentina para productos agrícolas fueron sensiblemente recordadas. ${ }^{7}$

La llegada de este acuerdo llevó a un entusiasmo exagerado por parte de la administración argentina que casi inmediatamente anunció otro con el Acuerdo Europeo de Libre Comercio (EFTA por sus siglas en inglés) (MRREEyC, 2019) y el inicio de negociaciones con Brasil para un TLC con Estados Unidos (Niebieskikwiat, 2019b).

Los gobiernos de Mauricio Macri y Jair Bolsonaro y sus contrapartes europeas y norteamericanas saben que la coyuntura política actual ofrece la oportunidad para que los países asuman el compromiso de desregulación comercial que pueden ser determinantes para consolidar un perfil de especialización primaria para países de la región (Lewkowicz, 2019).

Incluso aquel sentimiento los llevó a subestimar las señales alarmantes que aparecen del otro lado del Atlántico, como el rechazo austríaco que fue reducido a una mera cuestión electoral, y la creciente tensión de Francia e

\footnotetext{
6 Casi todos los objetivos que se planteó la Comisión Europea se obtuvieron, como puede desprenderse de la información que se difundió en 2016 para sus empresarios: un acceso fácil y privilegiado a un mercado grande y atractivo; la ventaja de un acceso privilegiado al Mercosur; el ahorro de impuestos aduaneros; oportunidades para los sectores más competitivos de la Unión Europea; acceso a materias primas a precios competitivos; acceso preferencial a un mercado de servicios; y lograr igualdad de condiciones para las empresas europeas en compras públicas (European Commission, 2016).

7 Como ha señalado Lucero, ha habido retroceso en el volumen ofrecido: La oferta de Europa al Mercosur para el año 2004 fue de 100.000 toneladas de carne. Luego de varios años se había acordado que no habría propuestas menores a los niveles del año 2004, al tiempo que la propuesta en el 2010 del Mercosur fue de abrir el merado a 400.000 toneladas. Lo acordado bajo la gestión de Cambiemos, sin embargo, fue 99.000 toneladas de carne (Lucero, 2019).
} 
Irlanda con Bolsonaro por la situación de los incendios en la zona amazónica, aunque esto podría ser una excusa de otros motivos más profundos (Avignolo, 2019). ${ }^{8}$

El presidente Alberto Fernández fijó la prioridad regional; y a pesar de las dificultades, el Mercosur ha sido privilegiado como el eje central de su diseño de inserción internacional: "nuestra vocación es fortalecer una integración regional y global que a su vez sea una integración social, productiva y democrática de nuestros países." (Fernández, 2020).

Las relaciones entre Buenos Aires y Brasília estuvieron atravesadas por muchas tensiones y no son escasos los análisis que no dudan en calificar a este momento como el peor en décadas (Labaqui, 2020). El Canciller Felipe Solá definió con sus propias palabras la situación:

Hoy se expresan en polos opuestos en cuanto a metodologías de cómo afrontar la pandemia: proteger la vida, en el caso de Alberto Fernández, y proteger la economía y dejar que la pandemia se expanda, en el caso del Bolsonaro... (OSG, 2020) ${ }^{9}$

Las diferencias no se limitan a las estrategias de cómo enfrentar a la covid-19, sino expresaron también visiones divergentes del mundo y, como consecuencia de ello, al rol del Mercosur. Ello se vio claramente en la decisión del gobierno argentino de dejar las negociaciones del mercado regional con Corea del Sur, Canadá y otros actores. Fue la evidencia más clara que la sintonía que se había observado

8 Una de las condiciones por las cuales los países con mayores intereses agrícolas de Europa aceptaron fue sobre la base de condiciones ambientales que se deben cumplir en el Cono Sur.

9 Desde el lado brasileño, las reiteradas críticas del presidente Bolsonaro apuntaron a acusar al gobierno de Fernández de llevar al país al socialismo (Coronavirus, 2020). 
en el pasado entre Argentina y Brasil está descompuesta por el resultado electoral de octubre de 2019 que puso a ambos países en esquinas opuestas. Bolsonaro profundizó y aceleró su agenda de integración neoliberal al mundo, mientras Buenos Aires se estaría alejando de ese paradigma (OSG, 2020).

La insistencia en "flexibilizar" al Mercosur también ha ido avanzando desde la firma del acuerdo de comercio regulado con la Unión Europea, como quedó claro en la reunión del bloque en Santa Fe (Argentina) en 2019, donde se resolvió dejar en libertad de acción a cada uno de los socios regionales para aplicarlos una vez sancionado localmente, sin esperar la aprobación de todos para la puesta en funcionamiento del instrumento negociado sea en un mismo momento. Esta ha sido una de las externalidades más eficientes para garantizar la continuidad del programa globalista, aún frente a los cambios políticos que están aconteciendo. ${ }^{10}$

Las señales del nuevo gobierno con respecto al acuerdo con el Viejo Continente han sido confusas, ya que se continúan con las negociaciones, pero de manera escasa, según destacó el Presidente Fernández a la agencia oficial española en motivo del lanzamiento del Plan Estratégico Automotor 2030: "Nosotros no tenemos problema que junto al Mercosur vayamos a unirnos a la Unión Europea, eso en la medida que esa decisión no afecte a nuestra industria”, también consideró que el Mercosur es un "espacio común desde donde enfrentar a la globalización" que debe ser asumida como un "hecho irreversible" tomado con

\footnotetext{
10 El extremismo neoliberal de Bolsonaro y su ministro Guedes es visto con cautela por el empresariado brasileño, y esta actitud puede acrecentar la desconfianza de la elite brasileña hacia su presidente, por lo que ella no solo estaría alimentada por el manejo de la crisis del coronavirus. Una muestra de ello fue que luego e aquella reunión se intentó acelerar el proceso de apertura anunciando la baja de un $50 \%$ el Arancel Externo Común, pero las presiones internas, sobre todo de los industriales, lo obligaron a replegar esas decisiones en diciembre último.
} 
"inteligencia” (Fernández, 2019). Pero la expresión del presidente es ambigua, ya que podría interpretarse un aval al instrumento regional o su rechazo, creemos que la respuesta a este interrogante podría mostrar cuáles son los límites del pragmatismo del gobierno argentino.

Según el diario La Nación, el gobierno argentino no le gusta el acuerdo y está tratando de lograr consenso interno para rechazarlo, a su vez se encuentra presionado por Bolsonaro para avanzar (Jueguen, 2020). Aunque existió cierta ambigüedad, el Canciller Solá "sostuvo que hay que aceptarlo y sostenerlo porque hay una continuidad jurídica del Estado" (OSG, 2020).

Pero resulta claro, como señalaron Luciana Ghiotto y Javier Echaide, que las asimetrías se profundizarán y que las manufacturas europeas producirán una destrucción de la producción local de pequeñas y medianas empresas y disminuirán al comercio dentro del propio Mercosur (Echaide y Ghiotto, 2020).

\section{El ascenso chino}

El ascenso de China fue estimulado principalmente por la demanda de consumo norteamericano y relevó un problema estratégico, ya que, a diferencia de Japón su antiguo proveedor, no estaba subordinado a los Estados Unidos, promoviendo lo que Giovanni Arrighi denominó "bifurcación" (Arrighi, 2007, p. 16).

El Sistema Internacional parece operar a favor de Beijín, ya que como indicó el autor italiano, en consonancia con Henry Kissinger (2012), señaló que "el resultado de la debacle iraquí puede muy bien marcar el surgimiento de China como auténtico vencedor de la guerra estadounidense contra el Terror" (Arrighi, 2007, p. 17).

Mucho de su asombroso crecimiento está atado a las actuales condiciones de la economía mundial, en particular la estadounidense. Los capitales llegan a sus costas para 
promover la producción industrial, sostenida por un uso de la mano de obra intensiva y barata, que encuentra en Estados Unidos su principal destino exportador. De este comercio bilateral, ampliamente favorable a Beijín, les permitió comprar bonos del tesoro norteamericano que ayudan a financiar tanto su déficit público como privado para garantizar su nivel de consumo. ${ }^{11}$

En los primeros tiempos de la Posguerra Fría, la política exterior china buscó que su accionar internacional estuviera regido por la formación de un escenario policéntrico (Estados Unidos, Rusia, Europa, Japón y China), limitando las tendencias hegemónicas de Estados Unidos y la necesidad de asociarse con otras naciones en desarrollo contra un orden mundial injusto (Jiang, 2008). Por ello, combinó los llamados "Cinco Principios de la Coexistencia Pacífica" que marcaron su posición como país periférico ${ }^{12}$ con las recomendaciones más instrumentales de Deng Xiaoping ${ }^{13}$ y que a medida que fue ascendiendo escalones en el escenario internacional asistimos a un alejamiento de estos últimos, y la reafirmación de los primeros.

Desde el inicio del 2000, los documentos oficiales chinos dieron cuenta del incremento de su presencia en la región, junto a África y Asia, ${ }^{14}$ en donde buscó “mantener

\footnotetext{
11 Así funcionó "chimérica” según la expresión de Neil Ferguson (2005).

12 Esto se refuerza con la continuidad de los Cinco Principios de la Coexistencia Pacífica de 1953: respeto mutuo por la integridad territorial y soberna de los Estados, pacto mutuo de no agresión, no injerencia en los asuntos internos e igualdad, y ventaja mutua de los acuerdos (Moncada Durruti, 2011).
}

13 Deng incorporó inicialmente cinco principios directrices en 1989 (los conocidos como "24 caracteres") que se extendieron a seis en 1993 (y 28 caracteres) y que son los siguientes: observar y analizar los acontecimientos internacionales con calma, asegurar nuestra posición, ocultar nuestras capacidades y esperar el momento adecuado, ser buenos en mantener un perfil bajo, nunca liderar la reivindicación, y llevar a cabo oposición de carácter medido (Moncada Durruti, 2011).

14 La búsqueda de nuevas fuentes de provisión energética se justificó en el hecho de que las reservas chinas de carbón, petróleo y gas representan el $70 \%$, el $11 \%$ y el $4 \%$ del nivel global. Y desde el punto de vista alimenticio, con el ascenso a la clase media de unos 600 millones de personas en 2015 y el proceso de urbanización 
la estabilidad social, y para ello, es imperativo un suministro constante de materias primas para que la fábrica del mundo y la urbanización, los dos motores económicos no queden estrangulados" (Cardenal y Araújo, 2012, p. 18).

El aumento de la presencia oriental inicialmente se hizo bajo una estructura triangular (Estados Unidos, China y América Latina) en donde Washington tendría el rol de una potencia global, Beijing el de una potencia regional y América Latina una región subordinada (Tokatlián, 2008).

En aquel contexto ocurrió el reconocimiento de China como una economía de mercado por parte de Argentina y de Brasil en 2004. Ello puso en movimiento a los dirigentes de la Unión Industrial Argentina (UIA) y de la Federación de Industrias del Estado de San Pablo (FIESP), que a pesar de sus diferencias se reunieron el 24 de noviembre de 2004 para acordar una estrategia conjunta de rechazo a la medida.

El gobierno argentino señaló la existencia de una serie de cláusulas en el convenio que le permitiría al país aplicar salvaguardas hasta el año 2008, pero que incluso no descartaban utilizar legislación antidumping o la aplicación de aranceles frente a prácticas desleales. La acción conjunta empresaria llevó a los gobiernos argentino y brasileño a dar señales de que se utilizarían diferentes instrumentos de protección e incluso se podrían implementar mecanismos comunes.

Pero luego de la redacción del Libro Blanco sobre América Latina y el Caribe (China, 2008), el país asiático dejó de ser un socio predominantemente comercial ${ }^{15}$ para asumir un rol como proveedor de inversiones y de

\footnotetext{
que restó unos 8 millones de hectáreas a la producción agrícola, se presume que a fines de esta década China solo producirá el $75 \%$ de los alimentos que demande (Jiang, 2008).

15 El comercio se multiplicó por diez entre 2004 y 2014, llegando a unos 292.000 millones de dólares (Vidal, 2014).
} 
financiamiento. Estimaciones privadas indicaron que entre 2011 y 2014, la Inversión Extranjera Directa china en la región creció de un 29 \% anual y pasó de representar del 13 $\%$ al $21 \%$, siendo sus principales destinos Brasil, Venezuela y Perú (Schumalen, 2014).

Tras la crisis de 2008, dejó de ser exclusivamente un proveedor de manufacturas a nivel global, receptor de inversiones y soporte financiero del déficit norteamericano y ello hizo crujir las bases de "chimérica".

El anuncio del "sueño chino" por parte de Xi Jinping fue la sistematización conceptual de ese viraje. El líder del Partido Comunista Chino lo presentó como una síntesis de las acciones llevadas adelante por Mao y Deng, aprovechando sus virtudes y desechando sus defectos, representando un gran desafío para el nuevo elenco gobernante. Consistió en tres objetivos básicos: reorientar las pautas de crecimiento, atender los problemas ambientales globales y

134 convertir a China en un país de renta media.

El primero de ello consistía en reorientar las pautas de desarrollo a partir de inversiones y exportaciones ( $45 \%$ del PBI) por un mayor consumo interno. Para ello, se buscó reducir la elevada tasa de ahorro de un $50 \%$ y recuperar la porción en el comercio mundial que antes era del $8 \%$ y en 2014 fue del $4 \%$-por las políticas de Estados Unidos y la Unión Europea, principales destinos del comercio chino-. El consumo interno de China representa el $37 \%$ de su producto bruto interno, pero se especuló oficialmente que "crecerá entre un $8 \%$ y un 11,5\% a lo largo de la próxima década.” (Vidal, 2014, n.p.) China fue receptora de inversión extranjera directa, sin embargo, en los últimos años se convirtió también en un exportador de inversiones ${ }^{16}$ hacia África, fundamentalmente en

\footnotetext{
16 Es muy difícil establecer a cuánto asciende el total de inversiones chinas en el mundo, ya que gran parte de ella se instrumenta por medio de paraísos fiscales.
} 
infraestructura, ${ }^{17}$ y América Latina,${ }^{18}$ donde se estaría expresando de manera latente el criterio de permisibilidad extrabloque puigiano. ${ }^{19}$

El segundo propósito consiste en atender los problemas ambientales globales, ya que el crecimiento económico de China fue uno de los mayores responsables por las emisiones de carbono a la atmósfera, afectando a sus ciudades e incluso llevando lluvia ácida más allá del Océano Pacífico, aunque se mostró distante de las acciones multilaterales, como en los Acuerdos de París.

El último objetivo, convertirse en un país de renta media, le podría impedir seguir creciendo a los ritmos actuales, por sustentarse en las ventajas ocasionadas por la existencia de una mano de obra intensiva con salarios bajos. Para el año 2015, la clase media china ascendía a unos 600 millones de personas, con unos 130 millones de población flotante que opera como mano de obra de reserva. El crecimiento restó tierras para la producción agrícola que son escasas, y sumado al aumento de la demanda energética, volcará al país a buscar en el exterior lo que no consiga internamente (Klare, 2012).

La promoción de la Nueva Ruta de la Seda busca la creación de infraestructura que garantice sus exportaciones, así como el acceso a materias primas que le permitan consolidar su crecimiento y aumentar su influencia global.

Como hemos explicado, la Argentina ensayó un despliegue de su estrategia de inserción en una estructura

\footnotetext{
17 Centrales eléctricas, ferrocarriles, puertos y proyectos mineros, etc.

18 Un ejemplo de ello fue el abandono de la estrategia triangular en América Latina que Beijing desarrollaba, ya que no mira más a EE.UU. Otro dato significativo es que la inversión china no posee las condicionalidades que existen en los fondos que parten desde la tríada.

19 Este consiste en cómo los países periféricos que pueden mantener sus márgenes de maniobra y no ser forzados a algún alineamiento, lo que no impide la disputa de las superpotencias por el dominio de esos espacios que podía desestabilizar el régimen internacional (Puig, 1980).
} 
triangular con dos vértices (Brasil y Estados Unidos), pero a partir del segundo mandato de Cristina Fernández de Kirchner aquella se complejizó por la emergencia de un nuevo vértice: la República Popular China, otorgándole un carácter de rombo (Busso, Actis y Rocío, 2017).

La calificación de China como socio estratégico potenció la creciente conflictividad con Brasil durante los mandatos de Cristina Fernández, que se sumaba a las políticas de restricción tomadas por el gobierno argentino, así como el menor crecimiento brasileño y su búsqueda de un acuerdo birregional con la Unión Europea (Lewkowicz, 2015).

Otro dato revelador fue la creciente presencia comercial china en el Mercosur que pasó en 2007 de unos 400 mil millones de dólares a 800 mil millones de la misma moneda en 2014, y que contrastó con la baja del comercio intrazona de unos 750 mil millones a 650 , convirtiéndose en un actor que fue desplazando la fuerte presencia regional (Vidal, 2014).

Una de las pruebas hacia el futuro del modelo de reindustrialización es el debate sobre las consecuencias de la Asociación Estratégica Integral (AEI) con Beijing. En 2014, el gobierno argentino se había fijado cuatro metas para la reunión entre Cristina Fernández y Xi Jinping realizada en Buenos Aires en julio: (1) lograr un mayor equilibrio comercial; (2) aumentar la inversión directa china en Argentina y viceversa; (3) puesta en marcha de logística integrada; y (4) profundizar la integración cultural (Rodríguez, 2014).

Estas metas se concretaron parcialmente gracias al viaje de Cristina Fernández de Kirchner en febrero de 2015 a China, donde se firmaron veintidós acuerdos en el marco de la AEI. Además, sostuvo que entre otros aspectos se obtuvieron inversiones para infraestructura energética y tecnología nuclear y espacial. Con ello el gobierno argentino logró el 
acceso a créditos a tasas más bajas y sin las condicionalidades habituales de los mercados financieros occidentales. ${ }^{20}$

Pero esta cuestión no salvó de las críticas que hicieron hincapié en que con ella se profundizaría el rol de productor de materias primas. Como señaló Ana Pedotti (2014), existe ese riesgo, ya que esas exportaciones "pasaron del $70 \%$ en 1992 al $90 \%$ en 2009” (p. 25).

Así lo entendió la UIA, la cual apuntó y criticó que las condiciones preferenciales otorgadas (adjudicación directa de obras, facultades discrecionales del Ejecutivo, contratación de mano de obra y facilidades para realizar otras actividades económicas de origen chino) no serían adecuadas para equilibrar la balanza comercial (UIA, 2015).

Nos parece importante resaltar que la AEI tiene potencialidades y dificultades y que sus logros dependen del uso que se haga con ella. Por ejemplo, revertir su carácter asimétrico es fundamental, pero no menos cierto que las importaciones si son de bienes de capital e insumos industriales nos garantice una diversificación de proveedores, como lo son los países desarrollados y también de Brasil. ${ }^{21}$

En este último aspecto existe una delicada línea, ya que estas nuevas oportunidades de diversificación económica pueden poner en riesgo al propio Mercosur, ya que como señaló Cesarín, en un reportaje en La Nación, estos instrumentos brindan "una puerta preferencial para alguien externo al bloque” (Mazzoni, 2015, n.p.).

La decisión de firmar la AEI, aunque no exenta de contradicciones, ${ }^{22}$ resultó el cambio más significativo de nuestro

\footnotetext{
20 Mientras Argentina recibía estos préstamos, tenía fuertes restricciones al crédito internacional por causa de los juicios en Nueva York llevado adelante por los fondos buitres.

${ }^{21}$ Estos acuerdos generaron inquietud en ese país, es muy ilustrativa la nota de Rubens Barbosa (2015).

22 El discurso industrialista de los gobiernos kirchneristas con la firma de este acuerdo chocó con el rol de proveedor de materias primas y los límites que esta relación le impuso a aquellos deseos.
} 
relacionamiento externo desde 1983, puesto que se adaptó al triángulo en el que se encontraba inmersa por un rombo, al sumar a la ascendente China.

El gobierno de Mauricio Macri tuvo avidez por atraer inversiones occidentales en detrimento de las provenientes de los emergentes, como lo manifestó en el viaje a Alemania en 2016: "China hizo enormes inversiones en nuestro país. Está muy bien, lo valoro. Pero sentimos que es más fácil el trabajo en común con Europa” (Macri, en Vázquez, 2016, p. 4).

Este rechazo se observó en la intención de "revisar" la AEI en lo referido a la construcción de represas en Santa Cruz y a la cooperación en investigación espacial, por ejemplo. (Tomas, 2016) Pero este revisionismo encarado por el gobierno argentino se encontró con "una dura negociación" según el Embajador Guelar. (Ortelli, 2016, p. 42)

Por otra parte, Macri se mostró sensible ante la preocupación norteamericana del aumento de la influencia de China en la región, aunque la primarización de las exportaciones acerca al país a Beijing, lejos de las aspiraciones del presidente conservador y su modelo de inserción económica.

A pesar de ello, Xi Jinping invitó al presidente argentino a la reunión de la Franja Económica de la Ruta de la Seda, realizada a mediados de mayo de 2017 con la asistencia de 29 jefes de Estado o Gobierno, solo dos de la región -el otro fue Chile- y representantes de organismos multilaterales, como el Banco Mundial y el Fondo Monetario Internacional (FMI). Allí el presidente argentino buscó revertir la "gaffe" (desliz) de su gira europea al proclamar que "los próximos 10 años serán mejor que los 40 anteriores" en la relación bilateral; mostró un cambio en su diseño original (Macri, 2017).

Con la llegada de Alberto Fernández a fines de 2019, luego de cierto titubeo inicial, la pandemia dio lugar a una intensa cooperación que se vio plasmada con la llegada 
de millones de insumos sanitarios por vía aérea y naviera. Para Juan Luis González (2020), la generosidad del Beijing tiene entre otros objetivos lograr el abastecimiento de carne porcina, que hoy se encuentra afectada por una peste africana que mató 250 millones de cerdos, y la necesidad de encontrar un reemplazo, por ello se firmó un acuerdo en tal materia, cuestión que generó un amplio rechazo de sectores ambientalistas.

China aprovechó la promoción de la cooperación para mejorar su posición en otros rubros en Argentina, ya que extendió el Swap por unos 8 mil millones de dólares ${ }^{23}$ y se ha avanzado en conversaciones con la empresa Huawei:

La reunión de los funcionarios de Cancillería con Huawei cobra envergadura en momentos donde el Gobierno busca un acercamiento y una ayuda por parte de los Estados Unidos por la deuda. Es que Washington, al igual que la Unión Europea, Japón, Taiwán y Australia, entre otros, se oponen tajantemente al desarrollo de la gigante estatal china y pidió al mundo que eviten el uso de su $5 \mathrm{G}$ por los efectos negativos que tendrá para la seguridad de las naciones. (Lejtman y DiNatale, 2020, n.p.)

El Secretario de Relaciones Económicas Internacionales de Argentina, Jorge Neme, señaló que "tenemos que tener relaciones respetables, respetuosas y de mutua conveniencia, tanto con EE.UU. como con China” (Beldyk, 2020, n.p.).

\section{Conclusiones: problemas en el triángulo y la llegada del rombo}

Desde su creación, el Mercosur se constituyó en un útil instrumento de política exterior argentina para permitirle a

\footnotetext{
23 Es un mecanismo por el cual Argentina y China se comprometieron a intercambiar pesos y yuanes generados por el intercambio comercial entre ambos países en una fecha pautada.
} 
las diversas administraciones sortear las tensiones generadas en el triángulo en el que se hallaba inmersa.

Uno de sus lados se orientó a construir una relación madura con Estados Unidos, con un punto de equilibrio entre los modelos occidentalista y latinoamericanistas que confrontaron durante gran parte de la Guerra Fría. Sin embargo, esta nueva orientación no sería completa sin tener en cuenta la nueva disposición cooperativa hacia la región con acento en Brasil, cosa que en el pasado no ocurría, ya que las políticas occidentalistas presumían la confrontación regional.

Las diferencias estuvieron en los sentidos en los que se utilizó dicho triángulo con dos tendencias predominantes: la autonomista, que consistió en buscar márgenes de maniobra en el escenario internacional -como ocurrió durante los gobiernos de Alfonsín, Duhalde, Kirchner y Fernández de Kirchner que apuntaron a establecerlas con países de 140 similares recursos y valores-; y la occidentalista, que privilegió la relación con la potencia hegemónica, en las administraciones de Menem y De la Rúa. Si bien en principio las administraciones de Mauricio Macri y Alberto Fernández pueden ser ubicadas como globalista y autonomista, respectivamente, el nuevo marco lleva a repensar tanto las estrategias como los instrumentos para su concreción.

La administración de Mauricio Macri inscribió su accionar a favor de un sesgo neoliberal de la globalización o hiperglobalización según Rodrik (2011). Este proceso estuvo lejos de estar cristalizado, aún lo está, ya que la tríada que lo conducía, compuesta por Estados Unidos, Europa y Japón, estuvo atravesada por tensiones y desde el comienzo del nuevo milenio se sumaron China y los emergentes como actores relevantes que llevaron a una "bifurcación" en el sistema internacional (Arrighi, 2007).

El Gobierno conservador se manifestó en múltiples expresiones y acciones iniciales como el promocionado 
viraje hacia el Pacífico que no se reducía a la Alianza conformada por Chile, Colombia, México y Perú, sino que tenía como destino final la Asociación Transpacífica, lo mismo puede decirse del Acuerdo con la Unión Europea, cuya punta de riel era el Transatlántico (TTIP).

El Mercosur, principal instrumento de inserción internacional de la Argentina, fue desvalorizado inicialmente frente a otros polos como la Alianza del Pacífico -la asociación deseada por la administración macrista-, la UE y los Estados Unidos, y también fue reducido a ser la puerta de acceso a los dos primeros bloques (Malcorra, 2015).

La firma del acuerdo comercial entre la UE y el Mercosur es asimilable a esos ejemplos históricos, puesto que se acepta el rol de proveedor de manufacturas de los primeros (poniendo en jaque a las propias), pero no el de exportador de productos agropecuarios, ya que está sujeto a las políticas de subsidios, cuotas y reglamentación sanitaria que restringen esa función en rubros como lácteos, vinos, carnes, etc.

Además, la apuesta por la Unión Europea -claramente un actor secundario frente a Washington y Beijing- lleva a preguntarnos sobre la oportunidad de este acuerdo en el medio de una guerra comercial. Por si esto fuera poco, los aranceles impuestos afectarán la relación con la Unión Europea, dado que sus bienes sin las barreras encontrarán mercado en nuestras latitudes y podrán atemperar las restricciones impuestas por Washington.

Para esa gestión, el Mercosur tuvo un valor de "puente" a los acuerdos OMC-plus, la derecha conservadora argentina lo consideró como una atadura de la libertad de Argentina de vincularse con el "Primer Mundo", por ello, sus referencias fueron considerarlo como parte del "aislamiento", nunca se sintieron cómodos con él y prefieren la fuga hacia la Alianza del Pacífico. 
Con la llegada del gobierno justicialista de Alberto Fernández, a la histórica falta de coordinación con Brasil frente a China se sumó el virtual quiebre en las estrategias de inserción de Argentina y Brasil que nos lleva a no ser optimistas. Las fuerzas del sistema internacional (hiperglobalización y el ascenso de China) están operando, y es necesario llevar adelante maniobras que permitan recuperar capacidades.

\section{Alejandro Sinonoff}

Es Profesor de Titular de Historia General VI (UNLP) y de Política Exterior Argentina (UCALP) y Docente-Investigador del Instituto de Investigaciones en Humanidades y Ciencias Sociales (IdICHS) y del Instituto de Relaciones Internacionales (IRI), ambos de la UNLP.

\section{Bibliografía}

142 ARRIGHI, Giovanni. 2007. Adam Smith en Pekin: origenes y fundamentos del Siglo XXI. Madrid: Akal.

AVIGNOLO, María Laura. 2019. Francia e Irlanda critican a Bolsonaro y peligra el Acuerdo UE-Mercosur. Clarin, 34 ago. Disponível em: https://bit.ly/3aefOdt. Aceso em: 15 abr. 2021.

BARBOSA, Rubens. 2015. Política externa e interesse nacional. O Estado de São Paulo, São Paulo, 24 feb. Disponível em: https://bit.ly/2OPwlNo. Acesso em: $22 \mathrm{dez} .2020$.

BELDYK, Mariano. 2020. Tenemos que estar conectados con el mundo que no es lo mismo que abierto. Perfil, 18 jul. Disponível em: https://bit.ly/2QpZAXB. Acesso em 15 abr. 2021.

BUSSO, Anabella; ACTIS, Esteban, NOVELLO, María Rocío. 2017. La geometría de la Política Exterior Argentina (1989-2015): fin del diseño triangular e irrupción de un nuevo vértice: las relaciones con Estados Unidos, Brasil y China. In: BUSSO, Anabella et al. (coord.). Modelos de desarrollo e inserción internacional: aportes para el análisis de la política exterior argentina desde la redemocratización: 1983-2011, actores y temas de agenda. Rosario: UNR Editora. pp. 11-51.

CARDENAL, Juan Pablo; ARAÚJO, Heriberto. 2012. La silenciosa conquista china: una investigación por 25 países para descubrir cómo la potencia del siglo XXI está forjando su propia hegemonía. Barcelona: Crítica. 
CHINA. 2008. Documento sobre la Política China hacia América Latina y el Caribe. Beijing: Ministerio de Relaciones Exteriores de la República Popular China.

CORONAVIRUS: los dardos de Bolsonaro y las respuestas desde Argentina. Página 12, 15 maio. Disponível em: https://bit.ly/3e9sJyo. Acesso em: 22 dez. 2020.

ECHAIDE, J.; GHIOTTO, L. 2020. El Acuerdo entre el Mercosur y la Unión Europea: estudio integral de sus cláusulas y efectos. Buenos Aires: The Greens/EFA in the European Parliament; Fundación Rosa Luxemburgo; CLACSO.

EUROPEAN COMMISSION. 2016. Comprehensive free trade agreement with Mercosur: potential gains for the EU. Brussels: European Commission. Disponível em: https:/ /bit.ly/3tzdPs1. Acesso em: 15 abr. 2021.

FERGUSON, Niall. 2005. Coloso: auge y decadencia del Imperio Norteamericano. Barcelona: Debate.

FERNÁNDEZ avala el acuerdo Mercosur-UE si "no afecta" a la industria argentina. 2019. Agencia EFE, 17 dez. Disponível em: https://bit.ly/3mPCnKw. Acesso em: 22 dez. 2020.

FERNÁNDEZ, Alberto. 2020. Discurso del presidente Alberto Fernández al encabezar la apertura del periodo 138 de sesiones ordinarias del Congreso de la Nación. Casa Rosada, Buenos Aires. Disponivel em: https://bit.ly/3wYDQDa. Acesso em: 22 dez. 2020.

GONZÁLEZ, Juan Luis. 2020. Relaciones Carnales II. Noticias, v. 30, n. 2277 , pp. $20-25$.

IDAFE, Martin. 2019. Acuerdo UE-Mercosur: el presidente español pide que se acelere. Clarín, 22 jun. Disponível em: https://bit.ly/3e9s9AT. Acesso em: 15 abr. 2021.

JIANG, Shixue. 2008. La perspectiva de la política exterior china. In: PAZ, Guadalupe; ROETT, Riordan (ed.). La presencia de China en el hemisferio occidental: consecuencias para América Latina y Estados Unidos. Buenos Aires: Libros del Zorzal. pp. 39-57.

JUEGUEN, Francisco. 2020. El plan de Alberto Fernández para el acuerdo entre el Mercosur y la Unión Europea. La Nación, 10 mar. Disponível em: https:/ / bit.ly/3tlYaMh. Acesso em: 22 dez. 2020.

KISSINGER, Henry. 2012. China. Buenos Aires: Debate.

KLARE, Michael. 2012. Ser o no ser imperialista. Le Monde Diplomatique, n. 128 , p. 57.

LABAQUI, Ignácio. 2020. Paciencia estratégica se busca. El Estadista, 11 ago. Disponível em: https://bit.ly/2Q6iUcD. Acesso em: 15 abr. 2021. 
LEJTMAN, Román; DINATALE, Martín. 2020. El Gobierno promueve un acercamiento tecnológico y financiero con China que sorprendió a la Casa Blanca. Infobae, 15 abr. Disponível em: https://bit.ly/3a9iAAL. Acesso em: 22 dez. 2020.

LEWKOWICZ, Javier. 2015. Socios con la potencia económica mundial. Página 12, 8 fev. Disponível em: https://bit.ly/3x0szly. Acesso em: 15 abr 2021.

LEWKOWICZ, Javier. 2019. Estados Unidos ajusta las riendas. Página 12, 2 ago. Disponível em: https://bit.ly/3tmoJ3T. Acesso em: 15 abr. 2021. LUCERO, Juan. 2019. Integración desequilibrada. Página 12, 29 jul. Disponível em: https:/ /bit.ly/32gtNuK. Acesso em: 15 abr. 2021. MACRI prometió que Argentina será el supermercado del mundo. 2017. Cronista, 17 maio. Disponível em: https://bit.ly/3dhG6xj. Acesso em: 22 dez. 2020.

MALCORRA, Susana. 2015. Hay que lograr una política que represente la potencialidad de Argentina. Infobae, 1 de diciembre. Disponível em: https://bit.ly/2Nqi6dQ. Acesso em: 2 de diciembre.

MAZZONI, Carlos. 2015. Acuerdos con China: una estrategia que siembra dudas y temores. Años de Campo con Arturo Navarro, 22 fev. Disponível 144 em: https://bit.ly/2ORCYyN. Acesos em: 15 abr. 2021.

MEARSHEIMER, John. 2019. Bound to fail: the rise and fall of the liberal international order. International Security, v. 43, n. 4, pp. 7-50.

MERCOSUR. 2019. Acuerdo de Asociación Estratégica Mercosur-UE. Resumen informativo elaborado por el Gobierno argentino. Buenos Aires: MERCOSUR.

MONCADA DURRUTI, Mariola. 2011. Visión del mundo exterior de las cuatro generaciones de líderes políticos de la República Popular de China: evolución histórica y conceptual. Barcelona: Barcelona Centre for International Affairs.

MONTESA, Ferran; AZCÁRATE, Bianca. 2015. Una OTAN de la economía. Le Monde Diplomatique en Español, Madrid. Disponível em: https://bit.ly/2RuLHb6. Acesso em: 15 abr. 2021.

MRREEyC. 2019. Comunicado conjunto: cierre de las negociaciones Mercosur EFTA. Información para la prensa 334/19. Buenos Aires: Gobierno Argentino. Disponível em: https:/ / bit.ly/3fKQn3s. Acesso em: 22 dez. 2020.

NIEBIESKIKWIAT, Natasha. 2019a. Mercosur-UE: quieren firmar el acuerdo antes de las elecciones de octubre. Clarín, 7 jun. Disponível em: https://bit.ly/3e5ZCfp . Acesso em: 15 abr. 2021. 
NIEBIESKIKWIAT, Natasha. 2019b. Tras el pacto con Europa, Macri y Bolsonaro buscan avanzar en un acuerdo comercial con EEUU. Clarín, 5 jul.

OSG. 2020. Definiciones del Canciller Argentino Felipe Solá: política exterior y negociaciones comerciales. Buenos Aires; Observatorio del Sur Global.

ORTELLI, Ignacio. 2016. Represas: serán más chicas y reducen el impacto ambiental. Clarín, 7 maio.

PERFIL. 2014. Qué arriesga el Gobierno al aliarse con China y Rusia en busca de estabilidad. Perfil, 28 de diciembre de 2014. Disponível em: https://bit.ly/3gG4VoI. Acesso em: 15 abr. 2021.

PUIG, Juan Carlos. 1980. Doctrinas internacionales y autonomía latinoamericana. Caracas: Fundación Bicentenario de Simón Bolívar.

RODRÍGUEZ, Fabián. 2014. Relaciones entre Argentina y China: el gran salto adelante. Agencia Télam, 19 jul. Disponível em: https://bit.ly/3uMFnKq. Acesso em: 15 abr. 2021.

RODRIK, Dani. 2011. La paradoja de la globalización: democracia y futuro de la economía mundial. Barcelona: Antoni Bosch.

SCHUMALEN, Federico. 2015. Las potencialidades y los riesgos de la avanzada inversora de China en la región. Tiempo Argentino, 30 de marzo, pp. 4-6. Disponível em: https://bit.ly/3aCgFEY. Acesso em 27 abr. 2021.

SIMONOFF, Alejandro. 2014. "Informe anual de la política exterior del Gobierno argentino (marzo 2013-marzo 2014)”. Anuario 2014. La Plata, Instituto de Relaciones Internacionales.

SIMONOFF, Alejandro. 2017. Cambio en el mejor equipo de los últimos cincuenta años. Revista Relaciones Internacionales, v. 53, pp. 1-9.

SIMONOFF, Alejandro. 2018. El choque con la realidad y los cambios en el Palacio San Martín (marzo 2017-marzo 2018). La Plata: Instituto de Relaciones Internacionales.

TOKATLIÁN, Juan Gabriel. 2008. Una mirada desde América Latina. In: PAZ, Guadalupe; ROETT, Riordan (ed.). La presencia de China en el hemisferio occidental: consecuencias para América Latina y Estados Unidos. Buenos Aires: Libros del Zorzal. pp. 77-116.

TOMAS, Aurelio. 2016. Mientras gira hacia Occidente, Macri congela los proyectos rusos y chinos. Perfil, 23 jan. Disponível em: https://bit.ly/3dj5cvI. Acesso em: 22 dez. 2020. (link disponível)

UIA. 2015. Acerca del "Convenio Marco de Cooperación en Materia Económica y de Inversiones entre el Gobierno de la República Argentina y el Gobierno de la República Popular China”. Buenos Aires: Unión Industrial Argentina. 
Mercosur como política exterior argentina y sus desafíos actuales

VÁZQUEZ, Federico. 2016. La nostalgia por un mundo que ya no es. Le Monde Diplomatique, n. 206. Disponível em: https://bit.ly/3e9y6O4.

Acesso em: 15 abr. 2021.

VIDAL, Macarena. 2014. América Latina da la réplica a China.

El Pais, 20 set. Disponível em: https://bit.ly/2PXExMn. Acesso em: 15 abr. 2021. 


\section{MERCOSUR COMO POLÍTICA EXTERIOR ARGENTINA Y SUS DESAFÍOS ACTUALES}

\section{ALEJANDRO SIMONOFF}

Resumen: El Mercosur ha sido un instrumento exitoso para la estrategia de inserción argentina en el mundo. Si bien estuvo sustentado en la alianza entre Buenos Aires y Brasília, que hoy atraviesa un tiempo complejo, nos concentraremos en las dificultades que está atravesando ante los cambios operados en el orden Internacional: la pretensión de la tríada (Estados Unidos, Europa y Japón) de integrarlo a la hiperglobalización, mediante el Acuerdo con la Unión Europea; y la irrupción de China que impactó en la estructura regional.

Palabras clave: Política Exterior Argentina; Mercosur; China; Hiperglobalización.

\section{MERCOSUL COMO POLÍTICA EXTERIOR ARGENTINA E SEUS DESAFIOS ATUAIS}

Resumo: O Mercosul tem sido um instrumento de sucesso para a estratégia de inserção da Argentina no mundo. Embora apoiado na aliança entre Buenos Aires e Brasília que hoje atravessa um momento complexo, nos concentraremos nas dificuldades que ela atravessa diante das mudanças na Ordem Internacional: a reivindicação da Tríade (Estados Unidos, Europa e Japão) para integrá-la à hiperglobalização, por meio do Acordo com a União Europeia, e por outro lado, o surgimento da China que impactou a estrutura regional.

Palavras-chave: Politica exterior argentina; Mercosul; China; Hiperglobalização. 


\section{MERCOSUR AS ARGENTINE FOREING POLICY AND ITS CURRENT CHALLENGES}

Abstract: Mercosur has been a successful instrument for the Argentine insertion strategy in the world. Although it was supported by the alliance between Buenos Aires and Brasilia that today is going through a complex time, we will focus on the difficulties it is going through in the face of the changes in the International Order: the claim of the Triad (United States, Europe and Japan) to integrate it to hyperglobalization, through the Agreement with the European Union, and on the other, the emergence of China that impacted on the regional structure.

Keywords: Argentine Foreign Policy; Mercosur; China; Hyperglobalization. Recebido: 23/12/2020Ａprovado: 22/03/2021 